\title{
The effect of a home-based orofacial exercise program on oral aperture of patients with systemic sclerosis: A single-blind prospective randomized controlled trial
}

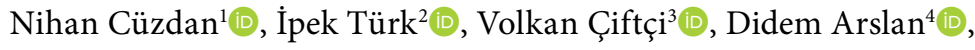 \\ Muharrem Cem Doğan ${ }^{3}$, İlker Ünal ${ }^{5}$ (D) \\ ${ }^{1}$ Department of Physical Therapy and Rehabilitation \& Rheumatology, Ballkesir Atatürk City Hospital, Ballkesir, Turkey \\ ${ }^{2}$ Rheumatology, Osmaniye State Hospital, Osmaniye, Turkey \\ ${ }^{3}$ Pediatric Dentistry, Çukurova University Faculty of Dentistry, Adana, Turkey \\ ${ }^{4}$ Department of Internal Medicine, Rheumatology, Çukurova University Faculty of Medicine, Adana, Turkey \\ ${ }^{5}$ Department of Biostatistics, Çukurova University Faculty of Medicine, Adana, Turkey
}

\begin{abstract}
Objectives: This study aims to evaluate the effect of a home-based orofacial exercise program on the oral aperture (OA) of systemic sclerosis (SSc) patients.

Patients and methods: This single-blind prospective randomized controlled study performed between March 2017 and January 2019 included $56 \mathrm{SSc}$ patients ( 3 males, 53 females; mean age $52.9 \pm 10.6$ years; range, 31 to 70 years) with an $\mathrm{OA}$ of $<40 \mathrm{~mm}$. Patients were divided into two groups. Group 1 ( $n=28$, mean age 53.8 \pm 9.6 years) was given orofacial exercise program twice a day for one month in addition to oral hygiene care advices, followed by no activity for the next month. Group 2 ( $n=28$, mean age $50.0 \pm 11$ years) received oral hygiene care advices for the first month followed by the same exercise program for the next month. Patients' OA was measured at baseline, and at first and second months.

Results: After the first month, OA increased in Group 1 ( $p<0.001)$, whereas no change was observed in Group 2 ( $p=0.579)$. At the end of two months, there was no additional increase in Group $1(p=0.352)$, while there was a significant increase in Group $2(p<0.001)$. There was no difference between OAs of the groups at the end of the trial $(p=0.564)$.

Conclusion: Our results suggest that home-based orofacial exercise program improves OA of SSc patients.

Keywords: Exercise, microstomia, oral aperture, rehabilitation, systemic sclerosis.
\end{abstract}

Systemic sclerosis (SSc) is a collagen disorder characterized by fibrosis that involves skin, mucosa, muscles and internal organs. The head and neck region is involved approximately in $70 \%$ of the patients with varying clinical manifestations. ${ }^{1}$ The oral and periodontal involvement mainly includes microstomia, mask-like facial appearance, periodontal diseases, osseous resorption and xerostomia. ${ }^{1-4}$ Microstomia is one of the major problems that causes multiple dysfunctions and affects quality of life (QoL) in SSc. ${ }^{5}$ Microstomia is defined as an interincisal distance (ID) less than $40 \mathrm{~mm}$, whereas severe microstomia is accepted as an ID less than $30 \mathrm{~mm} .{ }^{6}$ The prevalence of

Received: June 23, 2020 Accepted: July 29, 2020 Published online: January 14, 2021

Correspondence: Nihan Cüzdan, MD. Balıkesir Atatürk Şehir Hastanesi, Fizik Tedavi ve Rehabilitasyon Kliniği, Romatoloji Bölümü, 10100 Altıeylül, Balıkesir, Türkiye. Tel: +90 322 - 3386060 e-mail: nihancuzdan@hotmail.com

Citation:

Cüzdan N, Türk I, Çiftçi V, Arslan D, Doğan MC, Ünal i. The effect of a home-based orofacial exercise program on oral aperture of patients with systemic sclerosis: A single-blind prospective randomized controlled trial. Arch Rheumatol 2021;36(2):176-184. 
microstomia differs from 43 to $80 \%$ in patients with SSc. ${ }^{7-9}$ Decrement in ID can cause multiple problems including poor oral hygiene and dental caries and several functional problems such as difficulty in eating, chewing and speech. In an earlier study, our study group examined the factors that can affect malnutrition in individuals with scleroderma. According to the results, depression and microstomia appeared to be the most relevant factors with malnutrition of the patients..$^{10}$ Severe microstomia may worsen the nutritional status by having a negative impact on eating patterns of the patients. According to the study of Krause et al., ${ }^{11}$ poor nutritional status and reduced phase angle values were present in SSc patients with more active and severe disease; and also, they concluded that patients with malnutrition had a higher risk for SSc-related mortality. Thus, one can hypothesize that treatment of microstomia may help to improve the QoL and overall survival of the patients by improving nutritional status.

In many rheumatic conditions, exercise regimens have an important role in reducing pain and stiffness, preventing deformity, reconstructing muscle tissue and improving function. ${ }^{12}$ Microstomia is a specific complication of a rare disease; as a result, there is limited number of studies in the literature targeting treatment of this disorder. Conservative treatment methods including daily care such as brushing teeth regularly, usage of long handled brushes, powered toothbrushes, pilocarpine or artificial saliva in case of xerostomia may be helpful in oral hygiene maintenance in SSc patients. ${ }^{4}$ Besides daily oral care, physiotherapy seems to be an alternative method to increase mouth opening. ${ }^{13,14}$ Several combinations of orofacial exercise programs were experimented to reverse the progression of microstomia. ${ }^{2,6,13-15}$ Most of the exercises were focused on mouth stretching and oral augmentation which can improve oral aperture (OA) to a certain degree. ${ }^{2}$ However, previous studies have controversial results with various timelines and different exercise regimens, ${ }^{13,14,16,17}$ and according to a recent systematic review, the evidence appears to be weak. ${ }^{18}$

There is still no consensus on an effectively and safely applicable exercise regimen for this group of patients. Therefore, in this study, we aimed to evaluate the effect of a home-based orofacial exercise program on the OA of SSc patients.

\section{PATIENTS AND METHODS}

The study was designed as a single-blind, prospective, randomized controlled study with a two-month follow-up period, carried out in rheumatology outpatient clinic, between March 2017 and January 2019. SSc patients who fulfilled the American College of Rheumatology 2013 criteria with an OA of $<40 \mathrm{~mm}$ were included in the study. All patients had previously undergone dental examination by a dentist to exclude oral manifestations and dysfunction of temporomandibular joint that may interfere with attempts to exercise. Patients with missing teeth, dysfunction of temporomandibular joints, oral malignancy, recent dental procedures, multiple active digital ulcers and diagnosed psychiatric conditions were excluded. A total of 60 patients were included in the study. Patients were randomly divided into two groups. Randomization was performed using the sealed envelope method by opening the opaque envelope that the patient chose and patients were offered the allocated treatment regimen. Group 1 was given exercise regimen and oral hygiene care advices for the first one month, followed by no exercise but oral hygiene care advices for the next four weeks. Group 2, as the control group, received oral hygiene care advices for the first one month, followed by the exercise regimen twice a day along with oral hygiene care advices for the next four weeks (Figure 1). Oral care advices were given to each participant by a dentist involved in the study at their first visit. The reason of this design was to increase the sample size to be analyzed receiving exercise treatment, since scleroderma caused microstomia is a rare condition. With this protocol, we aimed (i) to investigate whether there is a benefit of the exercise program on microstomia; (ii) to observe the carryover effect of exercise therapy on microstomia after discontinuing the treatment over a period of time; and (iii) to estimate the intervention strategy by comparing the same medical approach with different sequences. The exercise program was demonstrated to the patients by a clinician at the first visit and handed to all patients printed as a manual to be performed every day for one-month duration. We also provided an exercise diary for all patients to be marked when they completed their daily 


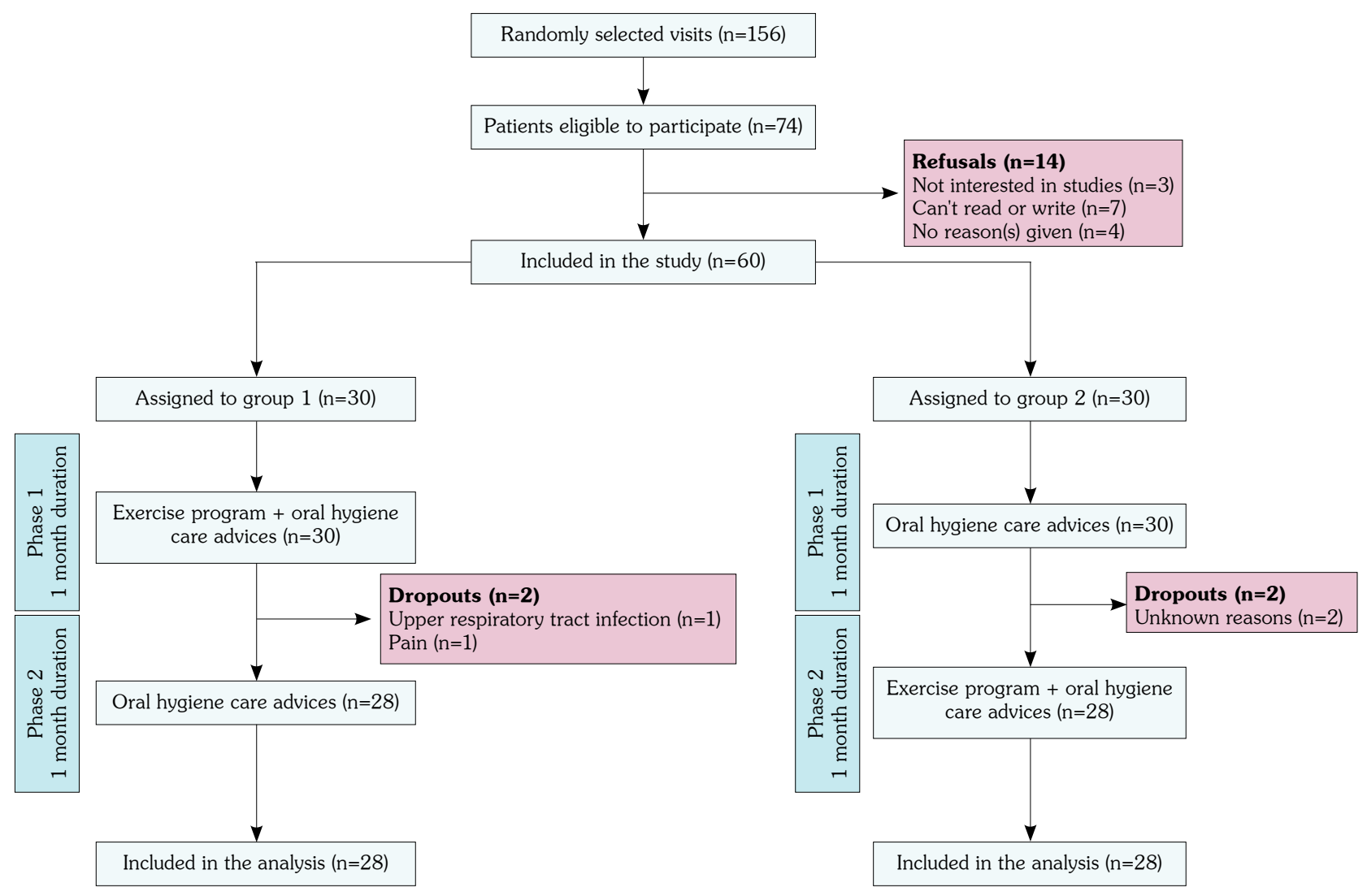

Figure 1. Flow diagram of participants in study.

exercise regimen and to note in case of pain or other complications. The exercise regimen was developed on the basis of previous studies and clinical knowledge. Exercise description was given in patients' native language (Figure 2).

A total of 56 patients ( 3 males, 53 females; mean age $52.9 \pm 10.6$ years; range, 31 to 70 years) completed the study. Four patients (two from Group 1 and two from Group 2) dropped out during the exercise program, one for complaint of pain and chubby lips while performing the exercises, one for upper respiratory tract infection, and two for unknown reasons. The mean age of patients in Group $1(\mathrm{n}=28)$ was $53.8 \pm 9.6$ years and $96.4 \%$ of the patients were female. Group 2 $(n=28)$ had a mean age of $50.0 \pm 11$ years and $92.9 \%$ female patients. The study protocol was approved by the Çukurova University, Faculty of Medicine Ethics Committee (10.06.2016; protocol: 54; clinical trial registration number: NCT04336475). A written informed consent was obtained from each patient. The study was conducted in accordance with the principles of the Declaration of Helsinki.

Patients' sociodemographic properties were recorded at the first visit. Disease duration was calculated from the first manifestation of the disease. The severity of the disease was evaluated by Medsger's disease severity scale. Patients were asked not to make changes in their medical treatments until termination of the study.

Patients' OA was measured at baseline, and at first and second months by an experienced dentist at the faculty of dentistry. All measurements were performed by the same dentist who was blinded to the exercise regimens to provide consistency. The OA was measured using the ID between the maxillary and mandibular central incisors in the midline. Patients were asked to open their mouth as wide as they could in the natural head position. The linear distance from the incisal edge of the upper central incisor to the incisal edge of the 

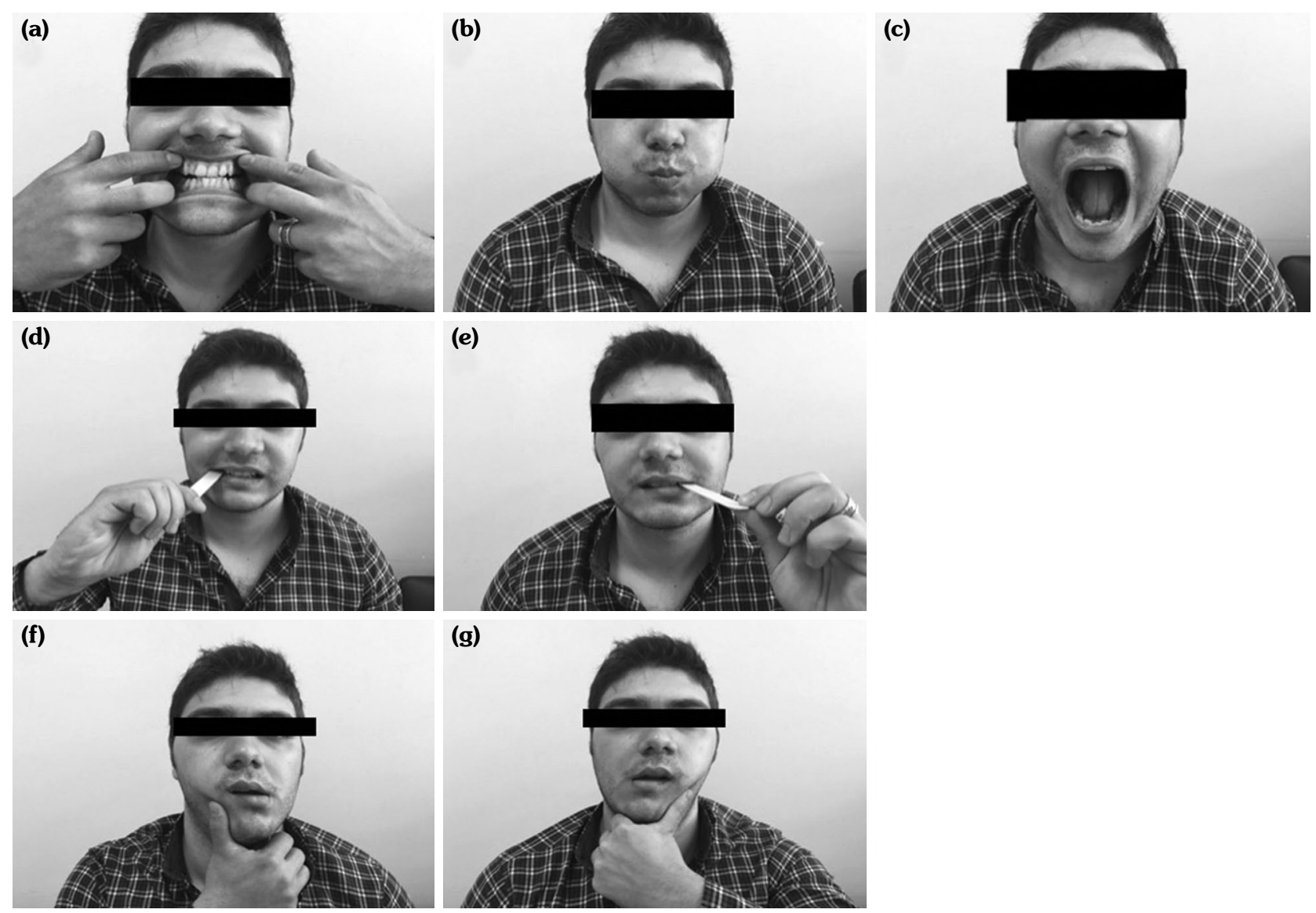

Figure 2. Daily exercise program given to patients with systemic sclerosis. Each exercise should be performed two times per day for five repetitions, holding each for $10 \mathrm{sec}$. (a) Participant stretches lips with fingers. (b) Participant inflates cheeks. (c) Subject keeps maximal mouth opening. (d, e) Participant bites a wood stick with right \& left molars. (f, g) Participant pushes chin to left and right sides.

lower central incisor was recorded using a dental bow compass and measured using a millimeter ruler. Each participant was measured three times every two minutes and the highest value of these three measurements was recorded. ${ }^{19}$

\section{Statistical analysis}

Statistical analysis was performed using the IBM SPSS version 20.0 software (IBM Corp., Armonk, NY, USA). Categorical variables were expressed as numbers and percentages. The Shapiro-Wilk test was used to confirm the normality of distribution for continuous variables. Parametric data were summarized as mean and standard deviation whereas non-parametric data were given as median and minimum-maximum. The Chi-square test was used to compare the categorical variables between the groups. For the comparison of continuous variables between two groups, the Student t-test or Mann-Whitney U test was used depending on whether the statistical hypotheses were fulfilled. To evaluate the change in $\mathrm{OA}$ measurements obtained in the time interval and to compare the trend in $\mathrm{OA}$ measurements between groups, the repeated measurements analysis was applied. In a former study, ${ }^{16}$ it was shown that the oral aperture measurement change in the exercise group was $2.81 \pm 3.25 \mathrm{~mm}$, and in the non-exercised group $-0.61 \pm 3.83 \mathrm{~mm}$. For the present study, based on these values, it was calculated that at least 24 patients should be taken per group to find this difference in 5\% error and $90 \%$ power significance. Considering the possible drop outs, the study was started with 30 patients per group. The level of $p<0.05$ was considered as statistically significant. 


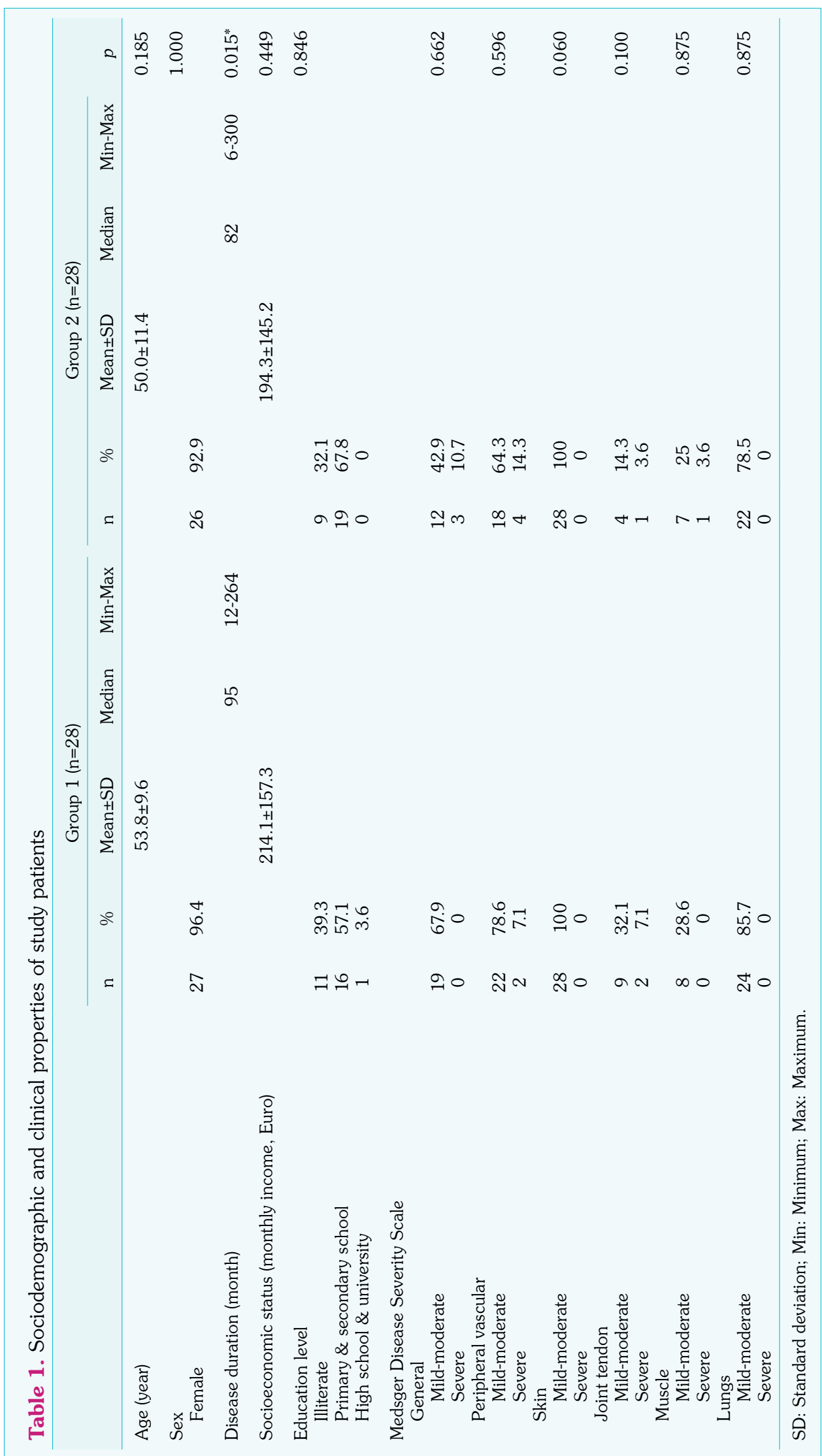




\begin{tabular}{|c|c|c|c|c|c|c|}
\hline & \multicolumn{3}{|c|}{ Post-treatment $1^{\text {st }}$ month/baseline } & \multicolumn{3}{|c|}{ Post-reatment $2^{\text {nd }}$ month/post-treatment $1^{\text {st }}$ month } \\
\hline & $\begin{array}{l}\text { Maximal mouth } \\
\text { opening (mm) }\end{array}$ & & & $\begin{array}{l}\text { Maximal mouth } \\
\text { opening }(\mathrm{mm})\end{array}$ & & \\
\hline & Mean \pm SD & $\begin{array}{l}\text { Mean difference } \\
\quad(95 \% \mathrm{CI})\end{array}$ & $p$ & Mean \pm SD & $\begin{array}{l}\text { Mean difference } \\
\quad(95 \% \mathrm{CI})\end{array}$ & $p$ \\
\hline Group 1 & $33.0 \pm 5.0 / 31.2 \pm 4.9$ & $1.94(1.19-2.69)$ & $<0.001$ & $33.4 \pm 5.3 / 33.0 \pm 5.0$ & $0.38(0.44-1.20)$ & 0.352 \\
\hline Group 2 & $32.9 \pm 6.1 / 33.1 \pm 5.5$ & $-0.09(-0.43-0.24)$ & 0.579 & $34.4 \pm 6.5 / 32.9 \pm 6.1$ & $1.71(0.91-2.50)$ & $<0.001$ \\
\hline
\end{tabular}

\section{RESULTS}

The flow diagram of the participants was shown in Figure 1. The descriptive data and baseline characteristics of the groups were shown in Table 1.

After four weeks, OA increased in Group 1 $(p<0.001)$, whereas no change was observed in Group $2(p=0.579)$. At the end of two months, the intra-group analysis showed no additional increase in Group 1 ( $p=0.352)$, but a statistically significant increase was detected in Group 2 regarding the measurement of OA $(p<0.001)$ (Table 2). The change obtained in the time interval and comparison of the trend in OA measurements between the groups were shown in Figure 3.

The mean OA measurements of all participants included in the study were $32.0 \pm 5.3 \mathrm{~mm}$ at

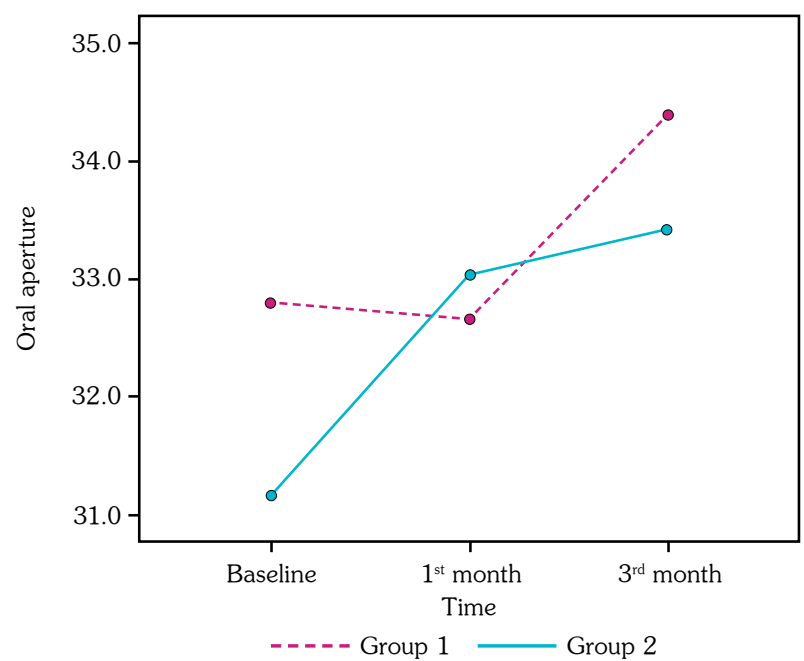

Figure 3. Change in oral aperture measurements in time interval. baseline and $33.9 \pm 5.9 \mathrm{~mm}$ at the end of the treatment $(p<0.001)$.

\section{DISCUSSION}

Systemic sclerosis is a chronic and relatively stable disease and improvement in QoL is the primary goal rather than a total cure. Decreased $\mathrm{OA}$, known as microstomia, is one of the major problems in SSc, which can cause malnutrition, dental hygiene problems and decreased QoL.1,3 The surgical treatment option of microstomia in patients with SSc is bilateral commissurotomy. However, because this surgical procedure can cause progressive vascular fibrosis and deficient wound healing, conservative therapy approaches are recommended to be the primary choice of treatment. ${ }^{20}$ Although there are several programs recommended to patients with SSc, there is no agreed-upon exercise program that is feasible and effective in improving microstomia. In the present study, the effectiveness of a newly designed stretching and strengthening exercise program was evaluated and shown to be effective in improving OA of scleroderma patients.

There are several studies investigating the effect of orofacial exercise programs in patients with SSc. In the study of Vitali et al., ${ }^{21}$ both stretching and strengthening exercises were given to four participants as adopted to participant' needs by a physiotherapist from eight to 12 sessions. They observed an increase in all participants: two participants with clear improvement after the exercise period, and the other two with a minimal increase at the baseline period. In the study of Maddali-Bongi et al., ${ }^{14} 20$ patients with SSc were divided into two randomized groups. Patients in 
the intervention group were given both face and hand exercises. The stretched mouth positions were held for about $30 \mathrm{~s}, 50$ to 60 times a day as a total of $30 \mathrm{~min}$ orofacial exercise on daily basis. They found an improvement in maximal mouth opening of the patients in the intervention group from 3.80 to $4.28 \mathrm{~mm}$ in nine weeks. Similarly, Pizzo et al. ${ }^{13}$ has shown the efficacy of elongation and mouth opening exercises on increment of the ID in 10 patients with severe microstomia. They observed a mean increase of $10.7 \mathrm{~mm}$ of maximal mouth opening over an 18-week period. Also, preliminary results of the study of Sydow et al., ${ }^{22}$ where they compared exercise with jaw motion device with mouth stretching exercises, showed that both types of interventions improve the maximal OA of the patients. In our study, we have observed a significant improvement of microstomia in a larger group of SSc patients compared with the aforementioned studies, particularly during the period of exercise program combined with oral hygiene care advices. The oral hygiene care advices solely have not improved OA in both groups to a significant level. Thus, we can conclude that orofacial exercise seems to be an effective intervention to improve the mechanical mouth disability of scleroderma patients.

Some studies included orofacial exercises as part of a physical therapy and rehabilitation program. Rannou et al. ${ }^{23}$ showed the superiority of a personalized supervised physical therapy program for one month followed by home exercises in SSc patients over usual care in terms of improvement in microstomia. In another study by Schouffoer et al., ${ }^{24}$ a 12 -week multidisciplinary patient treatment program, which consisted of general exercises, hand mouth exercises and educational sessions, was found more effective than regular outpatient care with respect to maximal mouth opening, six-minute walking distance, grip strength and health quality. According to a systematic review, ${ }^{25}$ facial rehabilitation is useful in improving mouth function, while the selection of patients, individually designed programs and the role of a multidisciplinary team are important factors that may affect the health benefit attained. Since the orofacial exercise program was shown to improve OA in our study, we believe that including orofacial exercises as part of the rehabilitation program for SSc patients would be beneficial.
There are several studies failing to demonstrate significant efficacy of rehabilitation programs on OA of scleroderma patients. In the randomized controlled study of Yuen et al., ${ }^{16}$ the participants received 6 min of oral augmentation and stretching exercise program. There was a significant increase in OA of the patients after a three-month period. However, they failed to show any difference between the intervention and the control group. Supporting results were reached by the study of Poole et al., ${ }^{17}$ in which they have failed to show significant improvement in their participants' OA after six months of a home-based orofacial exercise program. In both studies, oral augmentation and stretching exercises were given without a strengthening component and the daily stretching period was relatively shorter despite the long study period. Also, in the study of Yuen et al., ${ }^{16}$ the adherence rate was low, which may be one of the major factors that would have impacted their results. In the study of Uras et al., ${ }^{26}$ 12 months of orofacial exercise program was given to both experimental and control groups. However, the experimental group has received the program under the supervision of a trained nurse, whereas the control group had only brochures and digital videodisc explaining the program. In our study, similar to the results of Yuen et al., ${ }^{16}$ the comparison between two groups at the end of the first month revealed no differences. The reason might be that the oral hygiene care group had slightly higher values at the beginning of the trial. As a second explanation, the duration of the exercise program might not be long enough to reach a statistical significance when compared with the control group. The duration of the rehabilitation program and the follow-up period seems to have an impact on the results of the studies. In our study, we were able to give the exercise program for one month, which was relatively short. Our results were worse when compared to studies of Pizzo et al. ${ }^{13}$ and Maddali-Bongi et al. ${ }^{14}$ in regard to mean increase of $\mathrm{OA}$, indicating that longer duration of rehabilitation program seems to establish better results.

In our study, we also evaluated the outcomes after ending the exercise program over a period. After one-month of exercise-free duration, first group showed no decrement but a slight increase 
in OA which has not reached a significant level. This result may be due to the carry-over effect of the exercise program or the contributing effect of the daily oral care routine at the second month. Another explanation could be that some participants in Group 1 might have continued on performing the exercise program after the first month due to their learning. This could not be controlled since the program was home-based and this was a limitation of the study.

The different sequenced intervention programs both resulted in increment of $\mathrm{OA}$ at the end of the trial. According to this result, we may conclude that stretching and strengthening exercise combined with regular oral care is an effective method to improve OA of scleroderma patients with microstomia. There was no statistically significant difference between the groups, thus the timing of the exercise did not seem to have any effect on the final results. However, patients had significantly better outcome regarding OA improvement at the phase of the exercise program. So, we suggest that exercise regimens should be included in the selfmanagement care program as early as possible to reverse the process of mouth disability.

There are some limitations of the presented study. First, we observed patients only for two months; therefore, we can only interpret the short-term effects of the exercise program. Second, the exercise treatment was given as a home self-management program; thus, we were not able to control whether the participants have performed the exercise accurately or not. However, we provided a diary that would give feedback to help patients remain on the program. Third, we were not able to control the potential role of an immunosuppressive treatment if the patient was receiving at the time. We were also not able to evaluate the implications of the orofacial exercise program on the organ system functions in the present study. The strong points of the study were that our sample size was relatively larger from the previous studies, our adherence rate was high and no major complications were seen, which supported the feasibility of the exercise program. The exercise program consisted of both stretching and strengthening components and the measurements were performed by the same dentist who was blinded to the patient group and the process to prevent bias.

In conclusion, the results of this study suggested that the newly designed home-based orofacial exercise program in combination with oral hygiene maintenance might improve OA of SSc patients. Therefore, all patients are encouraged to add orofacial exercises as part of their rehabilitation program. Future studies with longer follow-up period and higher number of patients are needed to observe the long-term benefits and overall survival of the patients on orofacial exercise program.

\section{Declaration of conflicting interests}

The authors declared no conflicts of interest with respect to the authorship and/or publication of this article.

\section{Funding}

The authors received no financial support for the research and/or authorship of this article.

\section{REFERENCES}

1. Albilia JB, Lam DK, Blanas N, Clokie CM, Sándor GK. Small mouths. Big problems? A review of scleroderma and its oral health implications. J Can Dent Assoc 2007;73:831-6.

2. Hadj Said M, Foletti JM, Graillon N, Guyot L, Chossegros C. Orofacial manifestations of scleroderma. A literature review. Rev Stomatol Chir Maxillofac Chir Orale 2016;117:322-6.

3. Chung L, Lin J, Furst DE, Fiorentino D. Systemic and localized scleroderma. Clin Dermatol 2006;24:374-92.

4. Panchbhai A, Pawar S, Barad A, Kazi Z. Review of orofacial considerations of systemic sclerosis or scleroderma with report of analysis of 3 cases. Indian J Dent 2016;7:134-9.

5. Frantz C, Avouac J, Distler O, Amrouche F, Godard $\mathrm{D}$, Kennedy AT, et al. Impaired quality of life in systemic sclerosis and patient perception of the disease: A large international survey. Semin Arthritis Rheum 2016;46:115-23.

6. Naylor WP, Douglass CW, Mix E. The nonsurgical treatment of microstomia in scleroderma: a pilot study. Oral Surg Oral Med Oral Pathol 1984;57:508-11.

7. Eversole LR, Jacobsen PL, Stone CE. Oral and gingival changes in systemic sclerosis (scleroderma). J Periodontol 1984;55:175-8.

8. Marmary Y, Glaiss R, Pisanty S. Scleroderma: oral manifestations. Oral Surg Oral Med Oral Pathol 1981;52:32-7. 
9. Scardina GA, Messina P. Systemic sclerosis: description and diagnostic role of the oral phenomena. Gen Dent 2004;52:42-7.

10. Türk İ, Cüzdan N, Çiftçi V, Arslan D, Doğan MC, Unal I. Malnutrition, associated clinical factors, and depression in systemic sclerosis: a cross-sectional study. Clin Rheumatol 2020;39:57-67.

11. Krause L, Becker MO, Brueckner CS, Bellinghausen CJ, Becker C, Schneider U, et al. Nutritional status as marker for disease activity and severity predicting mortality in patients with systemic sclerosis. Ann Rheum Dis 2010;69:1951-7.

12. Gurcay E, Akinci A. Autoinflammatory diseases and physical therapy. Mediterr $J$ Rheumatol 2017;28:183-91.

13. Pizzo G, Scardina GA, Messina P. Effects of a nonsurgical exercise program on the decreased mouth opening in patients with systemic scleroderma. Clin Oral Investig 2003;7:175-8.

14. Maddali Bongi S, Del Rosso A, Galluccio F, Tai G, Sigismondi F, Passalacqua $\mathrm{M}$, et al. Efficacy of a tailored rehabilitation program for systemic sclerosis. Clin Exp Rheumatol 2009;27(3 Suppl 54):44-50.

15. Alantar A, Cabane J, Hachulla E, Princ G, Ginisty $\mathrm{D}$, Hassin $\mathrm{M}$, et al. Recommendations for the care of oral involvement in patients with systemic sclerosis. Arthritis Care Res (Hoboken) 2011;63:1126-33.

16. Yuen HK, Marlow NM, Reed SG, Mahoney S, Summerlin LM, Leite $\mathrm{R}$, et al. Effect of orofacial exercises on oral aperture in adults with systemic sclerosis. Disabil Rehabil 2012;34:84-9.

17. Poole J, Conte $\mathrm{C}$, Brewer $\mathrm{C}$, Good CC, Perella $\mathrm{D}$, Rossie $\mathrm{KM}$, et al. Oral hygiene in scleroderma: The effectiveness of a multi-disciplinary intervention program. Disabil Rehabil 2010;32:379-84.

18. Liem SIE, Vliet Vlieland TPM, Schoones JW, de Vries-Bouwstra JK. The effect and safety of exercise therapy in patients with systemic sclerosis: a systematic review. Rheumatol Adv Pract 2019;3:rkz044.

19. Yao K-T, Lin C-C, Hung C-H. Maximum mouth opening of ethnic Chinese in Taiwan. J Dent Sci 2009; 4:40-4.

20. Naylor WP. Oral management of the scleroderma patient. J Am Dent Assoc 1982;105:814-7.

21. Vitali C, Baldanzi C, Crispiatico V, Polini F, Ammenti $\mathrm{P}$, Montesano A, et al. Effect of impairment-oriented and function-oriented exercises on mouth function in subjects with systemic sclerosis. Folia Phoniatr Logop 2019;24:1-13.

22. Sydow E, Severi S, Van der Elst K, Verschueren P, Lenaerts $\mathrm{J}$, Westhovens $\mathrm{R}$, et al. A mixed method study to explore the feasibility and patient satisfaction of two different exercise programs in systemic sclerosis associated microstomia. Ann Rheum Dis 2019;78:1060.

23. Rannou F, Boutron I, Mouthon L, Sanchez K, Tiffreau $\mathrm{V}$, Hachulla E, et al. Personalized physical therapy versus usual care for patients with systemic sclerosis: A randomized controlled trial. Arthritis Care Res (Hoboken) 2017;69:1050-9.

24. Schouffoer AA, Ninaber MK, Beaart-van de Voorde LJ, van der Giesen FJ, de Jong Z, Stolk J, et al. Randomized comparison of a multidisciplinary team care program with usual care in patients with systemic sclerosis. Arthritis Care Res (Hoboken) 2011;63:909-17.

25. Mugii N, Hamaguchi Y, Maddali-Bongi S. Clinical significance and usefulness of rehabilitation for systemic sclerosis. Journal of Scleroderma and Related Disorders 2018;3:71-80.

26. Uras C, Mastroeni S, Tabolli S, Masini C, Pallotta S, Teofoli $\mathrm{P}$, et al. A comparison between two educational methods in the rehabilitation of the microstomia in systemic sclerosis: a randomized controlled trial. Clin Rehabil 2019;33:1747-56. 